\title{
The infusion rate of most disposable, non-electric infusion pumps decreases under hypobaric conditions
}

\author{
[La vitesse de perfusion de la plupart des pompes à perfusion non électriques \\ jetables diminue dans des conditions hypobares]
}

Masahito Mizuuchi MD, Michiaki Yamakage MD PhD, Sohshi Iwasaki MD, Akira Kimura MD, Akiyoshi Namiki MD PhD

Purpose: To examine the delivery rates of four disposable, nonelectric infusion pumps during hypobaric conditions.

Methods: Four models categorized by three different driving forces, one vacuum unit (Coopdech Syringector), one spring unit (Linear-fuser), and two elastomeric balloon-powered units (Multirate Infuser LV and Large DIB), were tested. Each infusion pump was placed in an airtight container, and the pressure in the container was decreased to 1,000,900, and $800 \mathrm{hPa}$. The catheter tip of each pump was exposed either to atmospheric pressure ( I,000 hPa) or to similar hypobaric conditions (800-1,000 hPa).

Results: Under normal atmospheric pressure, each pump showed an accurate delivery rate in the range of $-2 \%$ to $+8 \%$ of the set infusion rate $\left(4.0-5.0 \mathrm{~mL} \cdot \mathrm{hr}^{-1}\right)$. With the catheter tip exposed to atmospheric pressure, the infusion rate of each pump was reduced from $35 \%$ in the case of the Large DIB to $64 \%$ in the case of the Coopdech Syringector, depending on the magnitude of change in hypobaric pressure. When the pressure acting on the catheter tip was reduced to a level similar to that exerted on the pump body, infusion rate was reduced (by 19\%-27\%) in all three types of pump, and the Large DIB showed no significant difference in performance compared to normal atmospheric pressure.

Conclusion: The infusion rates of disposable infusion pumps are reduced under hypobaric conditions. Even though we still do not know how the epidural pressure changes under hypobaric conditions, clinicians should be aware that the infusion rate of disposable infusion pumps is decreased under hypobaric conditions.
Objectif : Vérifier les vitesses d'administration de quatre pompes à perfusion non électriques jetables utilisées dans des conditions hypobares.

Méthode : Nous avons testé quatre modèles classés selon trois différentes catégories d'éléments moteurs, un appareil à aspiration (Coopdech Syringector), un appareil à charnière (Linear-fuser) et deux appareils élastomères à ballonnet d'entraînement (Multirate Infuser LV et Large DIB). Chaque pompe a été placée dans un contenant hermétique dont la pression interne a été abaissée à I 000, 900 et 800 hPa. La pointe du cathéter de chacune des pompes a été exposée soit à la pression atmosphérique ( $000 \mathrm{hPa}$ ) soit à des conditions hypobares similaires (800-I 000 hPa).

Résultats : Soumise à une pression atmosphérique normale, chaque pompe a affiché une vitesse d'administration précise allant de -2 \% à $+8 \%$ de la vitesse de perfusion préalablement définie (4,0-5,0 $\left.\mathrm{mL} \cdot h r^{\prime}\right)$. Si la pointe du cathéter était exposée à la pression atmosphérique, la vitesse de perfusion de chaque pompe était réduite de $35 \%$, dans le cas du Large DIB, jusqu'à $64 \%$, pour le Coopdech Syringector, en fonction de l'importance du changement de pression hypobare. Si la pression sur la pointe du cathéter était réduite au niveau de celle qui était exercée sur le corps de la pompe, la vitesse de perfusion était réduite (de $19 \%$ à $27 \%$ ) pour les trois types de pompes. La performance du Large DIB r'a pas présenté de différence significative, comparée à la performance sous pression atmosphérique normale.

Conclusion : Les vitesses de perfusion des pompes jetables sont réduites dans des conditions hypobares. Même si nous ne pouvons encore expliquer les changements de pression péridurale observés dans des conditions hypobares, il faut savoir que la vitesse de perfusion des pompes jetables diminue dans de telles conditions.

From the Department of Anesthesiology, Sapporo Medical University School of Medicine, Sapporo, Hokkaido, Japan. Address correspondence to: Dr. Michiaki Yamakage, Department of Anesthesiology, Sapporo Medical University School of Medicine, South 1, West 16, Chuo-ku, Sapporo, Hokkaido 060-8543, Japan. Phone: 81-11-611-2111, ext. 3568; Fax: 81-11-631-9683; E-mail: yamakage@sapmed.ac.jp

Supported in part by a grant-in-aid (2001) for clinical research from Sapporo Medical University for the Promotion of Science,

Sapporo, Japan.

Accepted for publication January 23, 2003.

Revision accepted April 25, 2003. 
$\mathrm{T}$

EMPORARY epidural/iv catheter pumps are used to infuse analgesics in patients with post-traumatic pain, postoperative pain as well as chronic intractable pain. ${ }^{1-4}$ Several affordable, disposable, non-electric infusion pumps are currently available. The accuracy of the delivery rates of these portable infusion pumps has been investigated, ${ }^{5,6}$ and they can be used safely and reliably under normal conditions. It may be possible to use infusion pumps under hyperbaric conditions in patients with anaerobic infection, ${ }^{7}$ arteriosclerotic obliteration, or a critical condition such as carbon monoxide poisoning. ${ }^{8}$ There is a report on the performance of infusion pumps under hyperbaric conditions, ${ }^{8}$ and it is concluded that commercially available infusion pumps operating under hyperbaric conditions demonstrated substantial variations in performance and accuracy. We are exposed to changes in atmospheric pressure in daily life. Although changes in atmospheric pressure under normal conditions are not so large, patients who require infusions of analgesics for treatment of pain, who are transported to the hospital by plane or who live in cities located at high altitudes, can be exposed to very low atmospheric pressures. The pressure inside the cabin of a large jet airplane is maintained at about $800 \mathrm{hPa}$, although the air pressure outside the airplane is approximately $200 \mathrm{hPa}$ at 30,000 feet above sea level. Small airplanes, on the other hand, which are usually used for transporting patients, fly at about 10,000 feet or less above sea level (air pressure of $700-800 \mathrm{hPa}$ ) usually with no control of air pressure inside the cabin. There are also many areas in the world in which people live at altitudes higher than 3,000 feet above sea level (air pressure of 900 $\mathrm{hPa}$ ). Manufacturers, however, do not design or test their equipment for hypobaric use, and it is therefore important to examine the performance of various infusion pumps under hypobaric conditions.

In this study, we investigated the function and accuracy of four kinds of disposable, non-electric infusion pumps operated under hypobaric conditions.

\section{Methods}

Four disposable, non-electric pump designs, one vacuum (negative pressure), one spring, and two elastomeric balloon-powered units, were tested in this study. Data on expected flow rate, volume capacity, power mechanism, and cost are listed in the Table. The Coopdech Syringector (Daiken Medical, Tokyo, Japan) utilizes the sequential movement of two pistons to compress fluid contained in a specially designed device (Figure 1A). Negative pressure (vacuum) is used in the pump as a power device to deliver analgesics, the pressure being generated by injection of fluid into the pump. The Linear-fuser (Terumo, Tokyo, Japan) provides a constant internal pressure to drive the infusion system by a metal spring, which is housed within a cylindrical, durable, plastic casing. For these two pumps, a combined connector, micropore filter and flow restrictor unit $\left(2.0,4.0,6.0 \mathrm{~mL} \cdot \mathrm{hr}^{-1}\right.$ and $2.0,3.0,5.0 \mathrm{~mL} \cdot \mathrm{hr}^{-1}$, respectively) is interposed within the pump tubing to the catheter. Each of these two devices also has an external scale, which estimates the remaining volume of infusate in millilitres. The Multirate Infuser LV (Baxter Healthcare, Reading, MA, USA) relies on a balloon reservoir to supply sustained internal pressure. A flow restrictor is interposed within the pump tubing to the catheter $\left(2.0,3.0\right.$, and $\left.5.0 \mathrm{~mL} \cdot \mathrm{hr}^{-1}\right)$, and a filter is included in the balloon. The Large DIB (DIB International, Osaka, Japan) is also a balloon-powered unit. The delivery tubing between the pump and the connector does not restrict flow. The Luer body houses a filter and a size-controlled orifice, which act as a valve responsible for maintaining the flow rate at the predicted rate of $4.0 \mathrm{~mL} \cdot \mathrm{hr}^{-1}$. The latter two balloontype pumps tested have a plastic, hard covering outer case, which protects the balloon.

Distilled water (specific gravity of 1.0) was used to fill each pump to a volume of $80 \%$ of the infusion dose capacity recommended by the manufacturer. It is thought that the method of collecting fluid from the catheter and measuring the amount of fluid using a graduated syringe ${ }^{6}$ causes an error because of the evaporation of water. We therefore used another technique to accurately measure flow rate. Briefly, we constructed an airtight container with three ports for electric wiring, generating negative pressure, and catheter tip. Each infusion pump, resting on a precise mass measurement device $(\mathrm{EB}-430 \mathrm{H}$, Shimadzu, Kyoto, Japan), was placed in the container together with a digital barometre/altimetre (BR-88, Regulus,

TABLE Specifications of disposable, non-electric pumps used in this study

\begin{tabular}{lllll}
\hline & Expected flow rate $\left(m L \cdot h r^{-1}\right)$ & Volume capacity $(m L)$ & Power device & Cost $($ Can $\$)$ \\
\hline Coopdech Syringector (ISJ12-P2040) & $2.0,4.0,6.0$ & 120 & vacuum (negative pressure) & 48 \\
Linear-fuser (LF-H060S) & $2.0,3.0,5.0$ & 100 & Spring & 60 \\
Multirate infuser LV (C1155) & $2.0,3.0,5.0$ & 275 & Balloon & 68 \\
Large DIB (120140) & 4.0 & 200 & Balloon & 62 \\
\hline
\end{tabular}



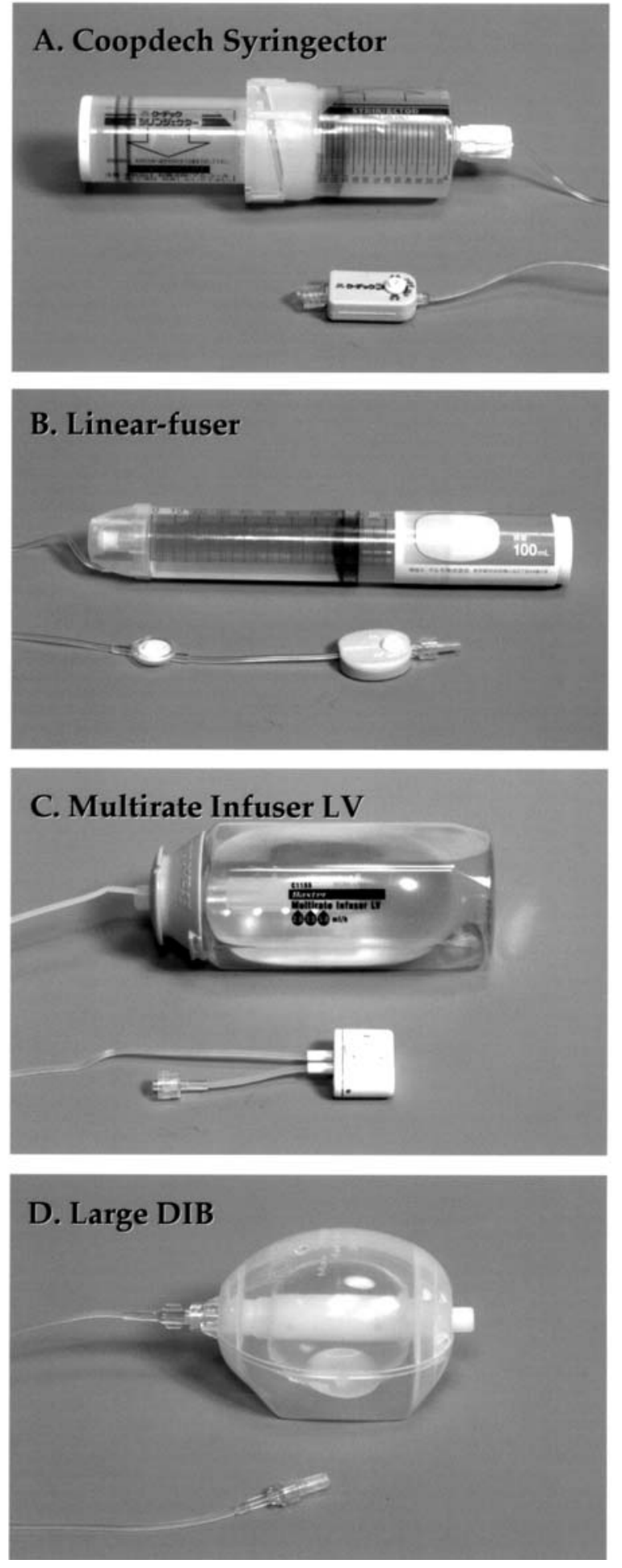

FIGURE 1 Four disposable, non-electric infuser pumps tested in this study: A) Coopdech Syringector (Daiken Medical Co., Osaka, Japan); B) Linear-fuser (Terumo Co., Tokyo, Japan); C) Multirate Infuser LV (Baxter Healthcare Co., Reading, MA, USA); and D) Large DIB (DIB International Co., Tokyo, Japan).

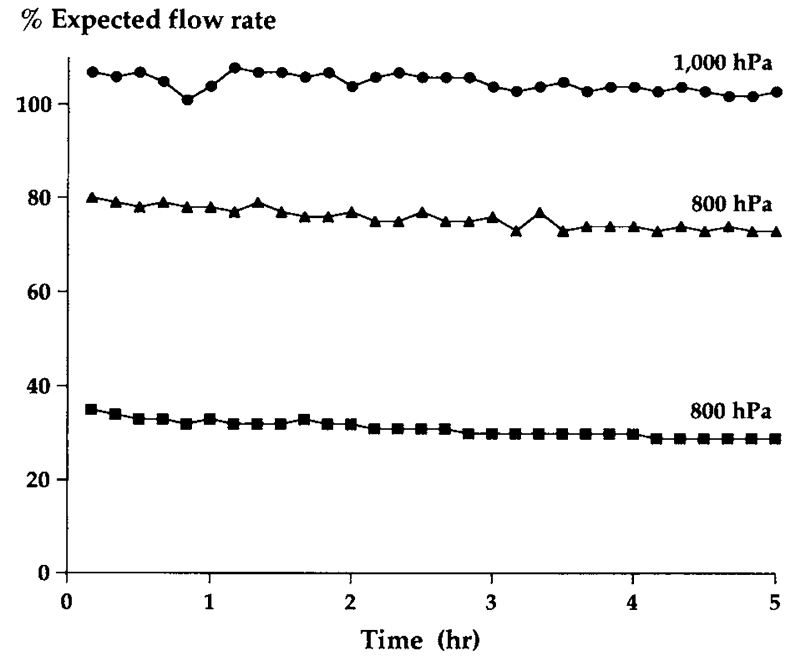

FIGURE 2 Typical time course of flow rates as percentage of expected flow volume $\left(4.0 \mathrm{~mL} \cdot \mathrm{hr}^{-1}\right)$ when the Coopdech Syringector was used under hypobaric conditions. $\bullet=$ normal atmospheric pressure at about $1,000 \mathrm{hPa} ; \mathbf{\square}=$ hypobaric pressure of $800 \mathrm{hPa}$ with the same pressure $(800 \mathrm{hPa})$ applied to the catheter tip; $\boldsymbol{\Delta}=$ hypobaric pressure of $800 \mathrm{hPa}$ with normal atmospheric pressure $(1,000 \mathrm{hPa})$ applied to the catheter tip.

Tokyo, Japan) and a digital thermohygrometre (SK$110 \mathrm{TRH}$, Sato, Tokyo, Japan). The pressure in the container was changed to $1,000,900$, and $800 \mathrm{hPa}$ by drawing out the air from the container, and the pressure was continuously monitored during the study. The catheter tip of each pump was exposed to atmospheric pressure $(1,000 \mathrm{hPa})$ or to hypobaric conditions similar to that of the pump body $(800-1,000$ $\mathrm{hPa}$ ). The infusion rates of the pumps tested were set to $4.0 \mathrm{~mL} \cdot \mathrm{hr}^{-1}$ for the Coopdech Syringector, 5.0 $\mathrm{mL} \cdot \mathrm{hr}^{-1}$ for the Linear-fuser, $5.0 \mathrm{~mL} \cdot \mathrm{hr}^{-1}$ for the Multirate Infuser $\mathrm{LV}$, and $4.0 \mathrm{~mL} \cdot \mathrm{hr}^{-1}$ for the Large DIB. The temperature and humidity of the room in which the study was conducted and in the airtight container were controlled at around $25^{\circ} \mathrm{C}$ and $50 \%$, respectively, by the use of an air conditioner. The atmospheric pressure remained stable during the study period $(1,002-1,005 \mathrm{hPa})$. The total weight of each pump was measured every ten minutes over a fivehour period using an automatic recorder (EP-50, Shimadzu, Kyoto, Japan) connected to the mass measurement device inside the container. The precise flow rate of each pump operating under hypobaric conditions was calculated from the decreasing weight of the pump. Because these are disposable pumps that may 
not be designed for reuse, we used a new pump for each experiment (five pumps for each model).

Data are expressed as raw data or means \pm SD. Estimated flow rate was used as the reference (100\%). Changes in the flow rate of each pump were analyzed using an unpaired Student's $t$ test. Other data were analyzed using one-way ANOVA for repeated measurements and Fisher's test was used as a post hoc test. In all comparisons, $P<0.05$ was considered significant.

\section{Results}

Typical time courses of flow rates as percentages of expected flow volume $\left(4.0 \mathrm{~mL} \cdot \mathrm{hr}^{-1}\right)$ when the Coopdech Syringector was used under hypobaric conditions at $800 \mathrm{hPa}$ are shown in Figure 2. Under normal atmospheric pressure, the pump delivered almost accurate flow rates $(103 \%-108 \%)$ during the study period. Under hypobaric conditions at $800 \mathrm{hPa}$ with the catheter tip exposed to normal atmospheric pressure, the flow rates decreased significantly to approximately $35 \%$ of the expected flow rates. When the catheter tip was exposed to the same hypobaric pressure as that of the body of the pump $(800 \mathrm{hPa})$, the decrease in flow rate was partially prevented (about $45 \%)$. The flow rates were almost constant during the study period.

Flow rates as percentages of expected flow volume for the four pumps under hypobaric conditions are shown in Figure 3. Under normal atmospheric pressure, deviation of flow rate from the expected flow volume was only $-2 \%$ to $+8 \%$. With the pump body exposed to hypobaric pressures and the catheter tip to normal atmospheric pressure, flow rates decreased significantly in all four pumps tested in a pressure-dependent manner. Under a hypobaric pressure of $800 \mathrm{hPa}$, the magnitude of decrease in flow rate was greatest in the Coopdech Syringector (decrease of about 64\%) and smallest in the Large DIB (decrease of about $30 \%)$. When the catheter tip of each pump was exposed to the same pressure as that acting on the pump body, the decrease in flow rate was completely prevented in the Large DIB and partially prevented in the other three pumps, the magnitude of decrease in flow rate being the largest in the Coopdech Syringector (about 25\%).

\section{Discussion}

The results of this study show that the infusion rates of four kinds of disposable infusion pumps, which are often used to provide postoperative continuous regional analgesia, are accurate under normal atmospheric pressure, with deviations of only $-2 \%$ to $+8 \%$ (Figure 3 ). However, the constancy of infusion rate of each pump is variable. ${ }^{5}$ The constancy of the infusion rate of the vacuum-powered Coopdech Syringector was high, as shown in Figure 2, but the infusion rates of the elastomeric- and spring-powered pumps were initially faster than expected and then decreased over the period of infusion (data not shown). Although there is evidence that changes in temperature around the flow-regulator may cause changes in infusion rates by more than $10 \%$ in some elastomeric pumps, ${ }^{5}$ the flow rates of all infusion pumps tested in this study were accurate under room temperature conditions $\left(25^{\circ} \mathrm{C}\right)$.

Epidural and subarachnoid infusions of analgesics for the treatment of pain can be used both in the hospital and at home. ${ }^{1,2,4}$ Epidural infusions of opioids and/or local anesthetics via a non-electric pump have been used for patients suffering terminal cancer pain. ${ }^{9}$ This method has also been used effectively in patients with non-malignant, chronic pain. ${ }^{10,11}$ Since some patients live in cities located at high altitudes and there is a possibility that patients will be transported to hospital by plane, it is important to know the function and accuracy of disposable, non-electric infusion pumps under hypobaric conditions. ${ }^{8}$ We found that the infusion rate of each pump was reduced significantly by $35 \%$ to $64 \%$ at $800 \mathrm{hPa}$ in a pressure-dependent manner when the catheter tip was exposed to normal atmospheric pressure $(1,000 \mathrm{hPa})$. When the body of the pump and the catheter tip were both under hypobaric conditions, the decrease in infusion rate was partially prevented (by $19 \%-27 \%$ ) in three of the pumps, and the infusion rate of the Large DIB was not significantly different from that under normal atmospheric pressure. These results indicate the importance of considering two factors. First, the performance of all infuser pumps tested (except for the vacuum-powered infusion pump Coopdech Syringector) does not depend on the power of atmospheric pressure. However, the infusion rate of all these pumps was influenced by hypobaric pressure. Therefore, atmospheric pressure has some effect on the delivery of fluid from the infusion pumps, even though these infusion pumps are powered by a spring or balloon. Second, application of pressure to the catheter tip influences the flow rate of disposable infusion pumps. The epidural space has a slight negative pressure (-1 to $-18 \mathrm{mmHg}$ ) compared to atmospheric pressure. ${ }^{12}$ Even though we still do not know how epidural pressure changes under hypobaric conditions, we have shown that the infusion rates of disposable infusion pumps decrease during exposure to hypobaric pressures. Only one balloon-powered infusion pump, the Large DIB, was not affected by hypobaric pressure when pressure at the catheter tip was similarly hypobaric, possibly because of a more powerful balloon drive. 


\section{A. Coopdech Syringector}

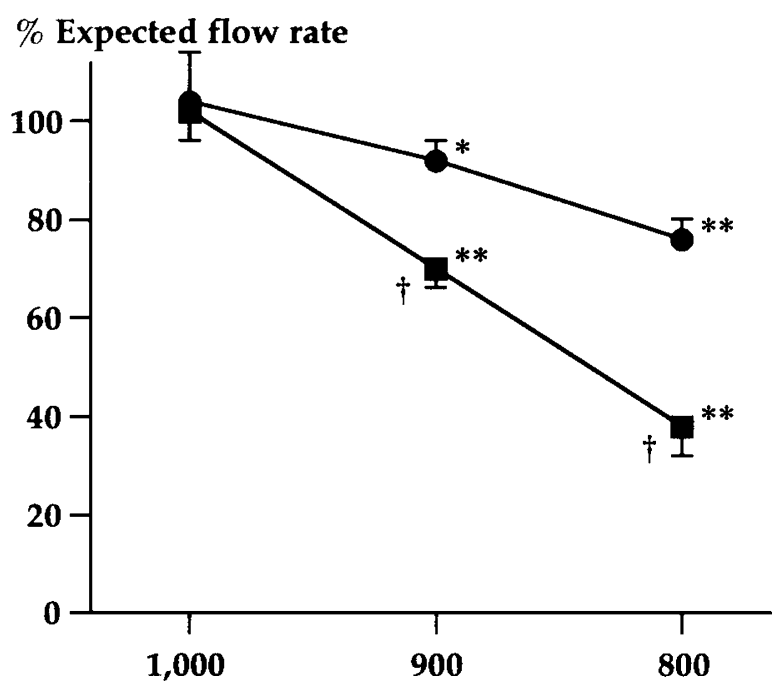

Hypobaric pressure applied to the pump (hPa)

\section{Multirate Infuser LV}

$\%$ Expected flow rate

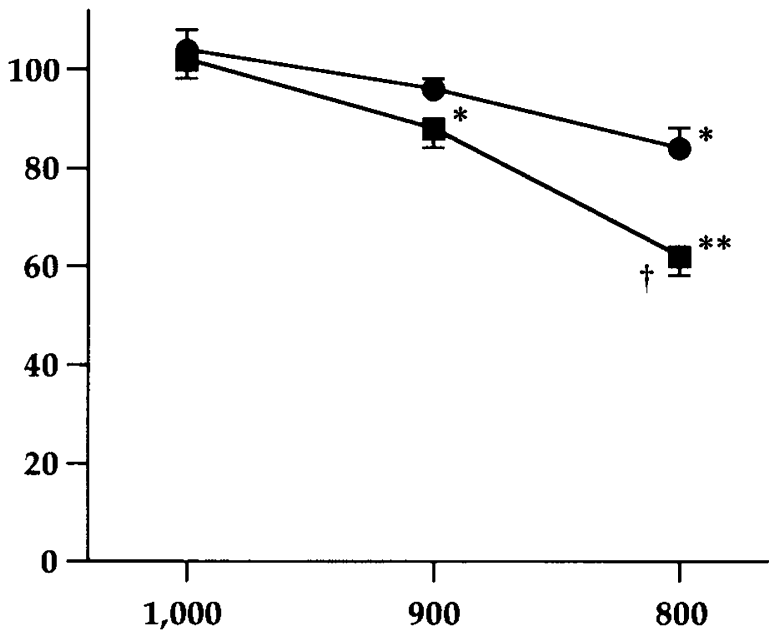

Hypobaric pressure applied to the pump (hPa)
B. Linear-fuser

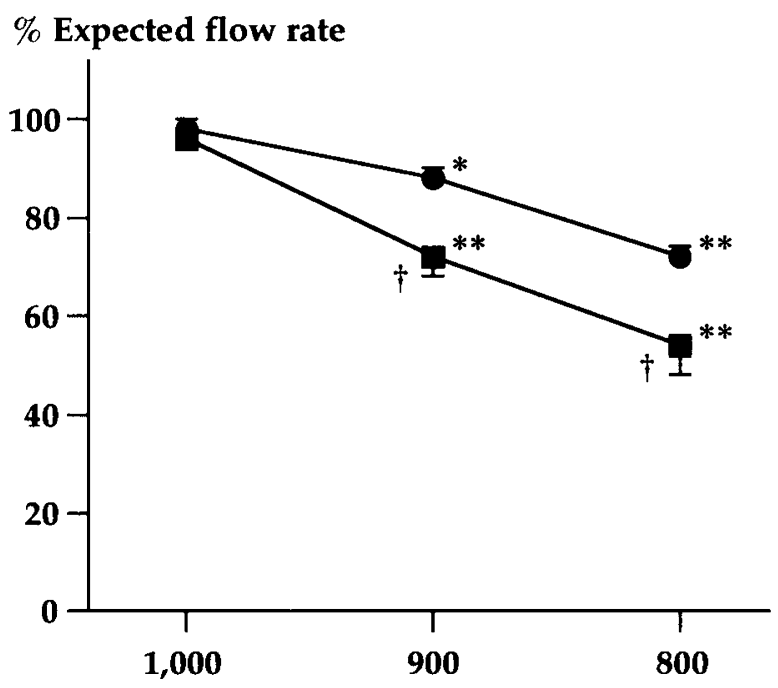

Hypobaric pressure applied to the pump (hPa)

\section{Large DIB}

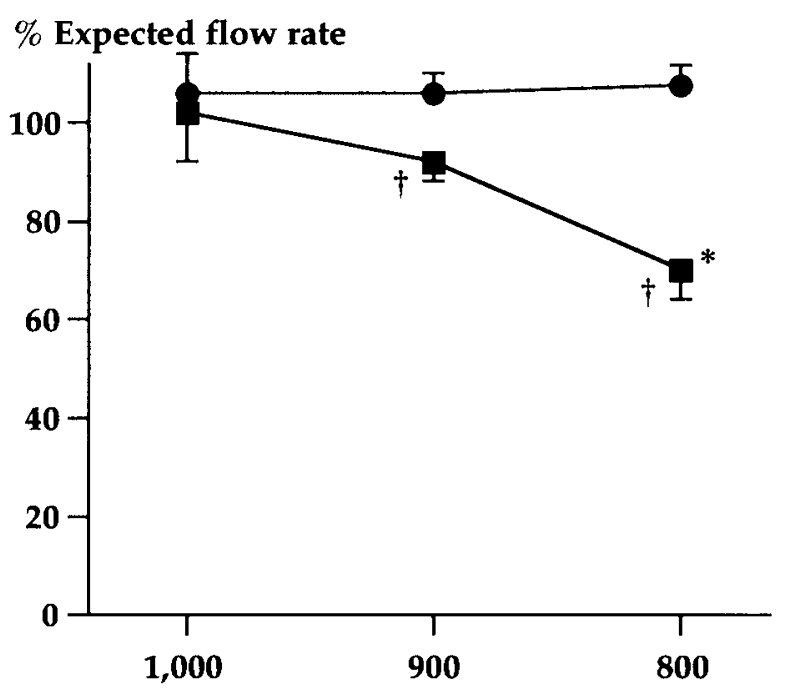

Hypobaric pressure applied to the pump (hPa)

FIGURE 3 Flow rates as percentages of expected flow volume of the four pumps under hypobaric conditions. $\bullet=\%$ expected flow rate with the catheter tip exposed to normal atmospheric pressure, $\mathbf{\square}=\%$ expected flow rate with the catheter tip exposed to the same hypobaric pressure. Data are expressed as means \pm SD. $n=$ five in each pump. ${ }^{*} P<0.05,{ }^{*} P<0.01$ vs normal atmospheric pressure. $\dagger P<$ 0.05 vs pump body and catheter tip under hypobaric conditions.

In conclusion, the infusion rates of most disposable infusion pumps can be significantly reduced under hypobaric conditions. It is recommended to use a volumetric infusion pump under conditions other than normal atmospheric pressure or, at a minimum, to monitor and adjust flow rates as appropriate to maintain drug delivery when using non-electric pumps under hypobaric conditions. 


\section{References}

1 Cousins MJ, Mather LE. Intrathecal and epidural administration of opioids. Anesthesiology 1984; 61: 276-310.

2 Hogan Q Haddox JD, Abram S, Weissman D, Taylor $M L$, Tanjan N. Epidural opiates and local anesthetics for the management of cancer pain. Pain 1991; 46: 271-9.

3 Banks S, Pavy T. A portable, disposable device for patient-controlled epidural analgesia following caesarean section: evaluation by patients and nurses. Aust $\mathrm{N} Z$ J Obstet Gynaecol 2001; 41: 372-5.

4 Rawal N, Axelsson K, Hylander J, et al. Postoperative patient-controlled local anesthetic administration at home. Anesth Analg 1998; 86: 86-9.

5 Ilfeld BM, Morey TE, Enneking FK. The delivery rate accuracy of portable infusion pumps used for continuous regional analgesia. Anesth Analg 2002; 95 : 1331-6.

6 Valente $M$, Aldrete JA. Comparison of accuracy and cost of disposable, nonmechanical pumps used for epidural infusions. Reg Anesth 1997; 22: 260-6.

7 Sánchez-Guijo JJ, Benavente $M A$, Crespo A. Failure of a patient-controlled analgesia pump in a hyperbaric environment. Anesthesiology 1999; 91: 1540-2.

8 Lavon H, Shupak A, Tal D, et al. Performance of infusion pumps during hyperbaric conditions. Anesthesiology 2002; 96: 849-54.

9 Ballantyne JC, Carr DB, Berkey CS, et al. Comparative efficacy of epidural, subarachnoid, and intracerebroventricular opioids in patients with pain due to cancer. Reg Anesth 1996; 21: 542-6.

10 Wermeling DP, Foster TS, Rapp RP, Kenady DE.

Evaluation of a disposable, nonelectronic, patient-controlled-analgesia device for postoperative pain. Clin Pham 1987; 6: 307-14.

11 Aldrete JA, Brown CA, rarcho KL. Cervical radiculopathy treated by infusion of epidural analgesics in homebound patients. J Clin Anesth 1994; 6: 33-6.

12 Thomas PS, Gerson JI, Strong G. Analysis of human epidural pressures. Reg Anesth 1992; 17: 212-5. 